\title{
Predatory journals exploit structural weaknesses in scholarly publishing
}

\author{
Jeffrey Beall \\ Retired, University of Colorado, Denver, CO, USA
}

Received 19 April 2018, Accepted 2 May 2018

Keywords: Ethics, Journals, Life sciences, Mathematics, Medicine, Misconduct, Open access, Physics, Psychology, Publication, Publisher, Predatory, Predatory publishers, Quality, Research, Responsibility, Scholarly publishing, Science, Social media

\section{Scholarly publishing's status quo}

The scholarly publishing process - from initial submission to final publication - has many weak points subject to exploitation [1]. Some open-access publishers have taken advantage of these vulnerabilities, profiting by cheating scholarly authors and the consumers of research, the readers. The open-access social movement has facilitated this exploitation [2], preferring to advance its ideology at the expense of good science. The result is that scholarly publishing is now operating in a crisis mode [3], with activist science and pseudo-science being presented as legitimate in scholarly literature. Academic evaluation is also suffering [4], with some researchers taking advantage of the easy acceptance the predatory publishers offer to quickly publish research articles, works that earn academic credit that lead to tenure and promotion and augment CVs shown to prospective employers. Before the advent of open-access journals, scholarly publishing was largely governed by a sustained implementation of the "gentlemen's agreement," which, according to Oxford English Dictionary (OED) Online is "an agreement which is not enforceable at law, and which is only binding as a matter of honour" [5,6].

With open-access journals, readers and libraries no longer have a say on which journals succeed or fail, an important quality-control function that's rapidly being lost. You cannot cancel a subscription to an open-access journal. Instead, the authors financing the publication of articles in open-access journals exercise the economic clout to determine the winners. Increasingly, the winners are the journals selling quick and easy acceptance of submitted articles at low fees [7].

There's nothing inherently wrong with the open-access publishing model, but to be successful, it must be managed properly, in a way that benefits science, those who carried

\footnotetext{
*Corresponding author: jeffrey.beall@ucdenver.edu
}

out and reported the research, and the readers and other "consumers" of the research. Not all open-access journals are predatory, nor are all subscription journals of high quality. Any human-based enterprise will prove imperfect over time.

Still, the gentlemen's agreement functioned, for a long time, to promote quality, honesty, and scientific integrity in scholarly publishing. The tacit agreement was made between researchers and publishers, with each agreeing to act in good faith and with integrity. The agreement was much easier to keep when authors did not have to engage in financial transactions with commercial publishers. This characteristic of gold (author-pays) open-access has opened the door to crookedness in science, and it's not just the publishers that lack integrity. Academic evaluation systems that still merely look at the number of published articles by a given scientist also help drive the corruption [8].

\section{Science Publishing Group}

Let me describe one particularly egregious predatory publisher to illustrate why predatory journals present such a serious threat. The publisher is Science Publishing Group [9] and it publishes, by my most recent count, 476 scholarly journals. It claims to be based on Fashion Avenue in New York City, but it is really based in Pakistan [10]. The publisher may make this false claim because potential customers may be more likely to assume a New York-based publisher is more legitimate than a Pakistanbased one. Looking at this publisher's articles and journals, it's easy to confidently classify it as a predatory publisher (at least it is for me). I have been monitoring this publisher for several years and remember when it first launched in late 2012 with 52 new journals. Yet the publisher is growing and thriving.

Obviously, it's not so easily identified as a predatory publisher by everyone. Its hundreds of journals have thousands of published articles, and it continues to expand 
and launch new journals. People are being fooled into believing SPG is a legitimate publisher or they are exploiting its automatic article acceptance to get easy academic credit, or both. Many of the articles it publishes are nonsense. For many years, I've used the article "Mathematical proof of the law of karma" [11] as an example in lectures I've given, an article that always draws laughter from the audience. It's published in SPG's American Journal of Applied Mathematics, a journal with an intentionally misleading title, as Pakistan is nowhere near America.

The publisher Science Publishing Group seems to have absolutely no morals or integrity and is a counterfeit scholarly publisher, designed to trick or serve the needs of scholarly authors around the world, and there are many like it - it is not an exception or an isolated case [10].

\section{Defensive action by researchers}

Concerned about the deleterious effects of predatory journals, scholars in many fields are taking action to alert their fellow researchers to their perils and to preserve research integrity in their fields. This is happening most often in medical fields, as they have been targeted intensively by predatory publishers. The publishers know that medical researchers often have foundation and government grants, funds that can be used to pay the author fees in their pay-to-publish journals, so they target bio-medical sciences researchers with incessant spam emails.

Dermatology is one such field where researchers are taking action to identify predatory journals [12] and warn others about them [13]. Another is nursing. A recent study [14] examined 140 predatory nursing journals from 75 publishers and made these significant findings:

- most of the journals had out-of-scope articles, such as articles on dentistry;

- only 115 journals stated the author fee on their websites and it was often hard to locate;

- ten journals boasted of a 2-3 day peer review, while 36 advertised a three-week peer review process;

- many of the journals studied falsely claimed they were included in scholarly indexes;

- among the authors, no nursing credentials were reported in $75.4 \%$ of the 4238 articles examined among the 140 journals;

$-65 \%$ of the articles had writing errors;

- the study's authors, expert nursing researchers, also examined each of the articles included in the study and found that $96.3 \%$ were rated as poor.

I think similar findings could be seen for other medical fields as well. Given that research is cumulative, the study's findings are particularly worrisome. Moreover, it is likely that many of the authors whose 4,238 articles published in the 140 journals earned academic credit or gained employment based at least partially on having their articles published in the journals [15].

\section{The Open-Access Social Movement}

The open-access movement has been stuck on promoting open-access as an ideological good rather than objectively evaluating whether it is the best solution to existing problems in scholarly publishing. I think the movement has averted its eyes to the problems and perils of predatory journals, preferring instead to promote openaccess and kill off subscription journals, despite the fact that thousands of subscription journals perform effective and highly selective peer review, add great value to published articles through copyediting, invest in publisher platforms that promote the articles, and carry on relationships with libraries that ensure articles are indexed in library discovery systems. Richard Poynder is a journalist who has been covering the open-access movement since its beginning. In a 2016 interview, he raised some significant issues about open-access and its advocates [16] :

"....OA advocates have tended to approach open access more as if it were a religion than a pragmatic response to the possibilities the network provides to improve both the research process and scholarly communication (which should surely be the ultimate goal of open access)".

"We have also seen OA advocates become addicted to cheerleading and the shouting of slogans,...". "The assumption was that all that was required was to "convert" colleagues".

"It also has to be said that the strategies proposed and/or supported by $O A$ advocates have often been cockeyednot least the concept of the article-processing charge $(A P C)$. That anyone ever thought pay-to-publish was a sensible way of disseminating research is most odd. Not only is it impractical, but it has played into the hands of any fly-by-night cowboy able to create a web site".

"I have also been surprised at how disconnected OA advocates are from the views of the wider research community - a tendency exacerbated by their habit of gathering together in their echo chamber of choice (conference hall, social media etc.) where their beliefs, prejudices and misconceptions are reinforced rather than subjected to a reality check".

OA advocates may not represent the whole movement, but Poynder's comments are significant because he has chronicled the open-access movement and the development of open-access publishing more closely than anyone else.

As an academic librarian, I see scholarly open-access publishing as something that is being forced on researchers rather than something that's being offered as a solution. To force open-access on researchers, numerous open access "mandates" have been implemented by universities and governments and funders [17]. Thus, open-access is a type of colonialism, but instead of one country colonizing another, the open-access movement represents a social movement invading an industry, in this case, the scholarly publishing industry.

Academic librarians have poisoned scholarly communication, using their often state-funded positions to ennoble themselves (and advance their careers) as combatants 
fighting the good fight against subscription journals (who can argue against free access?), eagerly accepting pay raises each year as they work to collectivize one industry and another, further diminishing the tax base.

There are many tight-knit communities of researchers centered on a field or sub-field who cooperatively edit journals — both subscription and open-access - and whose voluntarism and tight editorial control makes each of these community-supported journals successful. Such communities enable effective and meaningful communication among peers, and such journals should be models for all scholarly fields.

Despite the most far-reaching fantasies of open-access advocates, we are probably never going to see "universal open-access". Instead, we will continue to have a mix of scholarly publishing models, including various types of open-access and subscription publishing models. Preprint servers, which are benevolently funded and don't charge for submissions, will likely expand [17], solving the problems associated with the system of authors paying publishers to publish their works, but further eroding peer review, as preprints are usually published without it.

\section{Conclusion}

Scholarly publishing is vulnerable to exploitation both by publishers and by those seeking gratuitous academic credit. The honor system no longer guarantees that publishing ethics will be followed, so to be successful, academic journals must have safeguards built in that ensure integrity. Moreover, to succeed and gain broad acceptance, open-access needs to resolve the predatory publisher problem as such are "the dark dangerous force" of publishing [8]. It needs to earn respect and demonstrate that it's worthy of serving as a vehicle for communicating and preserving research knowledge. Given the status quo, much work needs to be done to achieve this.

\section{References}

1. Willinsky J, Wolfson L (2001), The indexing of scholarly journals: a tipping point for publishing reform? JEP 7. DOI: 10.3998/3336451.0007.202.

2. Beall J (2015), What the Open-Access Movement Doesn't Want You to Know, American Association of University Professors (AAUP), https://www.aaup.org/article/whatopen-access-movement-doesn $\%$ E2\%80\%99t-want-you-know
3. Pinfield S (2013), Is scholarly publishing going from crisis to crisis, Learned Publishing, 26, 85-88. DOI:10.1087/ 20130204.

4. Bagues MF, Sylos-Labini M, Zinovyeva N (2017), A Walk on the Wild Side: 'Predatory' Journals and Information Asymmetries in Scientific Evaluations, IZA DP No. 11041, 1-47. http://ftp.iza.org/dp11041.pdf.

5. Grosheide FW (1998), The gentleman's agreement in legal theory and in modern practice : the Dutch civil law perspective published in Rapports néerlandais pour le quinzième congrès international de droit comparé, , Intersentia Ltd., Cambridge, United Kingdom, 91-114 ISBN 905095-041-8. https://dspace.library.uu.nl/bitstream/han dle $/ 1874 / 42822 /$ b6 .pdf? sequence $=1 \&$ is Allowed $=y$.

6. "gentleman" OED Online. (2017), Oxford University Press, June 2017, Web. 21 August 2017.

7. Beall J (2012), Predatory Publishing: Overzealous openaccess advocates are creating an exploitative environment, threatening the credibility of scholarly publishing, The Scientist August 1, https://www.the-scientist.com/? articles.view/articleNo/32426/title/Predatory-Publish ing/.

8. Brücher BLDM (2018), Science Belongs to No One - And to Everyone, 4open 1(E1), 1-11. DOI: https://doi.org/ 10.1051/fopen/2017501.

9. Science Publishing Group http://www.sciencepublish inggroup.com/home/index.

10. Beall J (2018), Chapter 12 Scientific soundness and the problem of predatory journals, in: Pseudoscience: The Conspiracy Against Science, Kaufman AB \& Kaufman JC (eds.), pp 183-300 ISBN: 9780262037426.

11. Dorj J (2014), Mathematical proof of the law of karma, Am J Appl Math 2, 111-126. DOI: $10.11648 / \mathrm{j}$. ajam.20140204.12.

12. Beall J (2016) Medical publishing and the threat of predatory journals, Int $J$ Womens Dermatol 2, 115-116. DOI: $10.1016 /$ j.ijwd.2016.08.002.

13. Tosti A, Maddy AJ (2017), Ranking predatory journals in dermatology: distinguishing the bad from the ugly, Int $J$ Dermatol 56, 718-720. DOI:10.1111/ijd.13644.

14. Oermann MH, Conklin JL, Nicoll LH, Chinn PL, Ashton KS, Edie AH, Amarasekara S, Budinger SC (2016), Study of Predatory Open Access Nursing Journals, J Nurs Scholarsh 48, 624-632. DOI:10.1111/jnu.12248.

15. Beall J (2017), What I learned from predatory publishers, Biochemica Medica 27, 273-278. DOI: 10.11613/ BM.2017.029.

16. Poynder R (2016), Open access will remain a halfrevolution. [Interview by Michał Starczewski]. Retrieved from: https://otwartanauka.pl/in-english/experts-onopen-access/open-access-will-remain-a-half-revolution-in terview-with-richard-poynder.

17. Beall J (2013) The Open-Access movement is not really about open access, triple $C 11,589-597$. https: / / www.triplec.at/index.php/tripleC/article/view/525.

Cite this article as: Jeffrey Beall (2018), Predatory journals exploit structural weaknesses in scholarly publishing. 4open, 1, 1. 